\title{
The Role of Teachers' non-verbal Communication in ELT Classroom
}

Janak Singh Negi

\begin{abstract}
The role of non-verbal behavour in English classroom plays an important role for teaching content and skills. Based on this assumption, this article attempts to shed light on this hitherto unexplored area of research in the Nepalese context based on the observation by the author at various higher secondary schools in Nepal. The findings show that teachers' non-verbal behaviors play a highly important and essential role on learners' motivation in language classroom.
\end{abstract}

Key words: non-verbal communication, paralanguage, information processing

\section{Introduction}

Communication, which is used in everyday life from greeting a stranger to touching a lover, is an ongoing process of sending and receiving messages that enables human to share knowledge, ideas, thoughts, information, feelings, emotions, and attitudes. It requires a medium in which the communicated information is understood by both sender and receiver. There are two media, verbal and non-verbal, which are simultaneously used for communication. To be successful in communication it requires us to be both competent and experienced, not only in verbal communication but also in non-verbal one as well; because much of our communication takes place at the non verbal level. It cannot be an exception for ELT classroom as well because communication takes place there. Now question may arise what the non-verbal communication (NVC) is.

\section{Non-verbal Communication}

Communication takes various forms, one of which is oral or speech. However, when people speak, they normally do not confine themselves to the mere emission of words. Furthermore, they also use their hands, (gestures), head moments, eyes (eye contact), lips (smile), bodily postures and symbols to communicate which always accompany oral discourse-intended or not. The impact of these nonlinguistic cues in conversation is called non-verbal communication (NVC). It includes the 'messages other than words that people exchange' (Gregersen, 2007, p. 52). In this definition, messages are seen as symbolic, which are 'Silent infiltrators . . . that provide us with a mode for conveying messages without the use of verbal language (Dunn, 1999, p. 1). Going through these definitions we can say that nonverbal communication is the process of one person stimulating meaning in the mind of another person or persons by means of non-linguistic cues e.g. facial expressions, gestures etc. which can be synthesized in the words of Miller (1988) who defined nonverbal communication as 'Communication without words. . . it includes overt behaviors such as facial expressions, eyes, touching and tone of voice, as well as less obvious messages such as dress, postures and spatial distance between two or more people' ( $\mathrm{p}$. 3). 'It includes both behavior and communication' (Hickson and Stacks, 1993, p.5). In this article, I have also used the term, non-verbal communication and non-verbal behaviors interchangeably. We can say that it is a process whereby people, through intentional or unintentional manipulation of normative actions and expectations express 
experiences, feelings, and attitudes either singly or in combination with verbal behaviors in the exchange and interpretation of messages within a given situation or context and tell us about whether verbal messages are true, joking, serious, threatening and so on. The following differences between verbal and non-verbal communication will make this even clear. First, the majorities of nonverbal behaviors (NVBs) are intuitive and based on normative rules. There are not any clear-cut linguistic structures for non-verbal communication. On the other hand, 'verbal communication is highly structured and reinforced through an extensive formal and informal learning process' (Harris, 2002, p.153). Second, verbal communication is confined to the use of language. On the contrary, NVC delivers a message beyond the words. For the analysis, this is a useful division. However, 'nonverbal communication is so inextricably bound up with verbal aspects of the communication process that we can only separate them artificially' (Knapp, 1972 , p. v). In a nutshell, we can say that NVC is fewer rules bound than verbal communication and is judged more by the situational variables than the absolute correctness of the behavior.

\section{Forms of Non-verbal Communication}

Various forms of NVC that are used in language classroom include: kinesics, facial expressions, oculesics, haptics, proxemics, paralanguage, chronemics, physical appearance, olfactics, environmental factors and so on. Kinesics looks at bodily postures, facial expressions such as smile, frown, wrinkling the bow etc; and movements of the head and limbs whereas oculesics looks at the influence of visual contacts on the perceived massage that is communicated. Eye movement and eye contact as Khan (2001) says depict the focus, direction and duration of gaze in relation to other participants. For example, our eyes narrow when we are concentrating and pupils dilate when we are excited. Haptics describes touching behaviors. This category consists of physical contacts such as handshakes, patting on the shoulders and so on, whereas proxemics what Menninen and Kujanpaa (2002, p.3) call 'spatial behavior' is the 'physical distance we place between ourselves and others' (Helmer and Eddy, 2003, p.43), which indicates whether the relationship among the interlocutors is personal? social or public? And paralanguage is concerned with the non-verbal audio part of speech such as tone, pitch, intonation and pause etc which come alongside spoken language. Masterson (1996) and Boyd (2000) describe these as 'vocalics'. Finally we come to physical appearance which refers to the attributes of image such as attractiveness, height, weight, body shape, hair style, and dress and so on. These attributes can be classified into two categories: controllable e.g. clothes, hair style etc and less controllable e.g. skin color, height, body shape etc; on the contrary olfactics looks at interpersonal communication through smell which is concerned with scents or odor that comes from the perfumes and bodily hygiene. At last we come to chronemics, the study of the meanings, usages and communication of time, punctuality and so on and environmental factors which refers to the environmental setting e.g. pollutions, temperature, noise etc.

\section{The Functions of Non-verbal Communication}

By function of non-verbal communication what is meant is the message that the NVC cues convey. Non-verbal behaviors occur simultaneously with the verbal message and they substitute, complement, regulate and contradict the verbal message. Substitution of non-verbal message occurs when a non-verbal cue is used instead of verbal one. For example, a head node to indicate' yes', pat on shoulder to show 'intimacy' and so on. Non-verbal behaviors also compliment, expand or modify the verbal message. For example, a teacher looking confident while delivering the lecture in the class enhances the quality of teaching. Non-verbal message regulate the conversational flow as well. For example, gestures, head movements and many other behaviors indicate how the interaction should progress. The regulatory function as Capper (2003) says also serves to provide vital cues for the learners' interpretation of speech acts and considerably enhance conversation. Finally, non-verbal cues also 
contradict verbal message as in the case of 'irony' and 'satire'. In a nutshell, non-verbal communication expresses happiness, sadness, surprise, intimacy, seriousness, satire, formality, informality and so on via the use of various non-linguistic cues.

\section{Principles of Non-verbal Communication}

Non-verbal behaviors are innate and universal i.e. people in different cultures have a common understanding of non-verbal cues; however the total meaning of discourse can be culturally determined and differ in different countries. For example, as Davis (1990) says Caucasian schoolteachers associate students' avoidance of eye contact with deception, whereas Asian students see such avoidance as a sign of respect.

Most of the non-verbal behaviors are involuntary. For example, facial expressions such as blushing, sweating or yawning etc. are largely beyond the control of the individual. In such a case, the context and power relationships among participants play the vital role.

Non-verbal communication uses wide varieties of non-linguistic cues such as bodily postures, facial expressions, touching behaviors and so on simultaneously with the linguistic ones. These behaviors may change over time and across generations due to the changing cultural factors. For example, Nepalese male and female students in past did not use to sit together in the classroom. They even felt shy while talking but nowadays they shake their hands, sit and walk together. The role of nonverbal communication also 'vary depending on the age, sex, and the various culture involved'(Harris, 2002, p. 155).

Sometimes non-verbal behaviors may be expressed beyond the face to face conversation as in the case of telephone conversation. In such a case NVC is expressed via paralanguage.

\section{Importance of NVC in ELT Classroom}

Teacher creates more impression through NVC in the classroom than the knowledge of subject matter and verbal fluency. There is a language of body expression and motion that plays a pivotal role in the language classroom. Research studies done in classroom environments also suggest that nonverbal behaviors send clear and distinct messages. Moreover, these 'non-verbal messages can be a more explicit and candid means of determining intent than merely the spoken word alone' (Rosa, 2000, p. 1). Furthermore, Woolfolk and Brooks (1983) indicated that non-verbal behavior often influence the demeanor of teachers and students. Actually the success of both the student and teacher depends upon the effective communication between them in the class, but communication becomes handicapped without the proper use of non-verbal behaviors. In this regard, Stevick (1982) points out that:

The body language of a teacher is the most important thing in the class... it is the way you use your eyes, the distance you stand from your students, the way you touch or refrain from touching them all of these unnoticeable things in the class carry important signals which create a profound effect on your students' feelings of welcome and comfort with you (p. 6).

In general, it is true that NVC accounts for a large part of meaningful human communication. Actions, such as facial display, eye contact, body language or the way we wear our clothes, make hair style etc. speak louder than words and often help others make accurate judgments about our thoughts, feelings and intentions because they 'set the scene for total communication' (Mey, 1993, p. 224) and provide significant information about others emotional states' (Maxim and Nowicki, 2003, p.745), which is also supported by Mehrabian (1971) who claims that 93 per cent of the emotional meaning is transmitted as follows: 7 per cent is verbal expression, 38 per cent is vocal expression, and 55 per cent is facial expression (p.44). Thus, we can say that even if 'we speak with our vocal organs. . . we converse with our entire bodies, conversation consists of much more than a simple interchange of spoken words' Abercrombie (1973, p. 31). If we see different models of communicative competence we can easily access the significance of NVC. Hymes (1972), introduced the concept of communicative competence back in 1960s, believed that there were certain rules of use without which the linguistic or grammar 
rules were useless. Among many things needed for communicative competence, were also the rules of non-verbal communication of target language. Thus, he highlighted the rules of NVC as important as other grammar rules for learning a second language. Canale and Swain (1980) developed another model of communicative competence, which includes three main competencies: grammatical competence, sociolinguistic competence and strategic competence. In this model non-verbal communication strategies are highly emphasized in strategic competence (Khaniya, 2005, p. 27). Since the goal of language teaching is to develop the communicative competence, it becomes handicapped without the proper use of NVC and if we become aware of NVC, it may certainly enhance effective communication. Non-verbal behaviors, which are more subtle and can be used more often in the classroom are also the sign of psychological state of the teacher and should not be taken lightly. If the teachers' non-verbal behaviors are positive students enjoy the lecture and highly motivated to the teacher and the subject matter, on the other hand if the non verbal behaviors are negative students feel discomfort and may not be motivated to the subject matter and the teacher.

\section{Review of Related Literature}

Non-verbal communication is a fundamental aspect of human life from the moment we enter the world. Since then a number of NVC research have been carried out. Some of the recently carried out research in this field include: Boyd (2000), who carried out the research entitled Non-verbal Behaviors of Effective Teachers of At-risk African American Male Middle School Students. His study revealed that when effective teachers interacted with the at-risk African-American-male middle school students, they frequently were in close proximity, changed their voice inflections, established eye contact, invaded students' territories (were within two feet), and gestured to students. The same year, Rosa (2000) conducted the research on Understanding the role and potential impact of non-verbal communication in the primary inclusion classroom the purpose of which was to compare the non-verbal behaviors of students who are considered average in ability with those who are perceived as cognitively challenged while they are engaged in regular classroom instruction in both large and small groups settings. Her finding shows that in most of the cases the majority of nonverbal interaction occurred between students who sat in close proximity regardless of their cognitive ability. Likewise, Christopher (2002), Lewis (2005) and Hassan (2007) carried out researches on Nonverbal Communications. Christopher reached at the finding that males displayed more active nonverbal behavior than females; the result by Lewis showed that female students make eye contact more than the male students and smile more often in the classroom setting; and the study by Hassan showed that the college students are not only conscious of their teachers' NVC but are also biased towards certain types of non-verbal cues and behaviors. The present study is mainly based on the research carried out by the author in 2009.

\section{The Study}

This article is an extract from the research entitled Teachers' Non-verbal Communication and its Impact on the Learners' Motivation carried by the author at the Department of English Education, Tribhuvan University, Nepal (2009) in partial fulfillment for his Master's Degree (M.Ed.) in English Education. The research was carried out to identify the teachers' most frequently used nonverbal behaviors and find out its impact on the learners' motivation in the ELT classroom. (But in this article only second part is addressed) The sample population of 10 teachers and 80 (40 males 40 females) students were purposively selected from 10 different Higher Secondary Schools of the Kathmandu valley. The researcher used both the questionnaire (Appendix A) and the observation forms (not included in this article) as tools in the study that consisted of the components of non-verbal communication such as kinesics, facial expressions, oculesics, proxemics, physical appearance, paralanguage; and chronemics used in the classroom. 


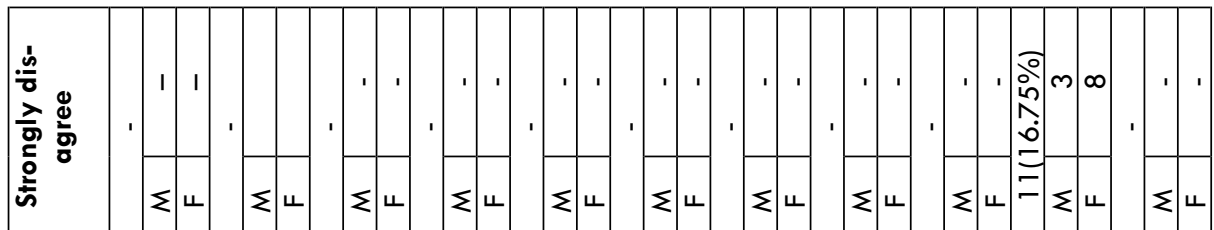

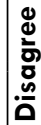

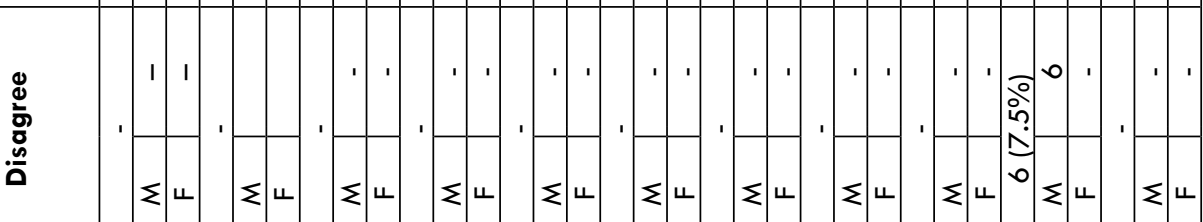

呈

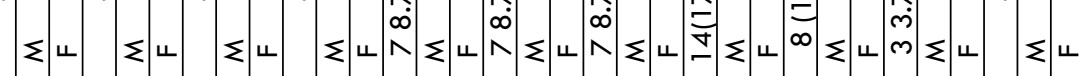
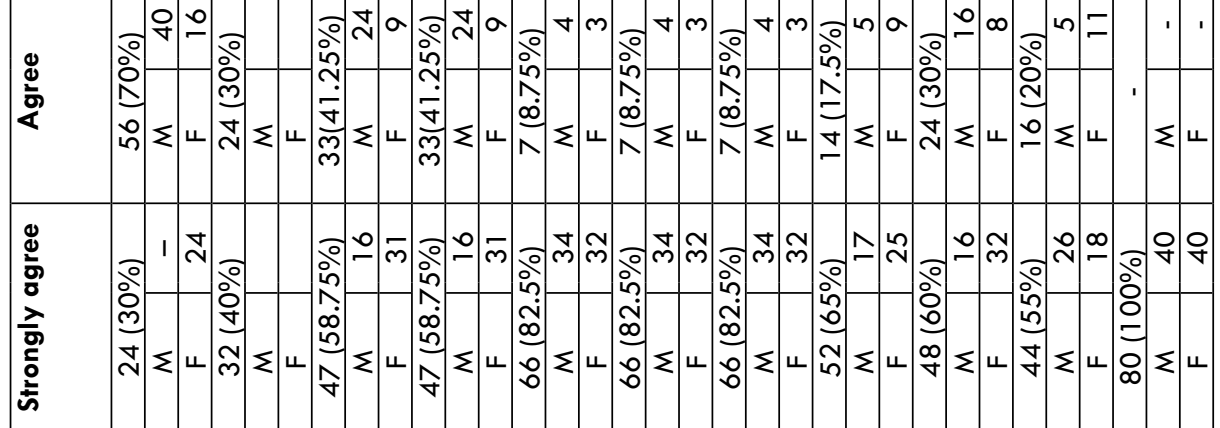

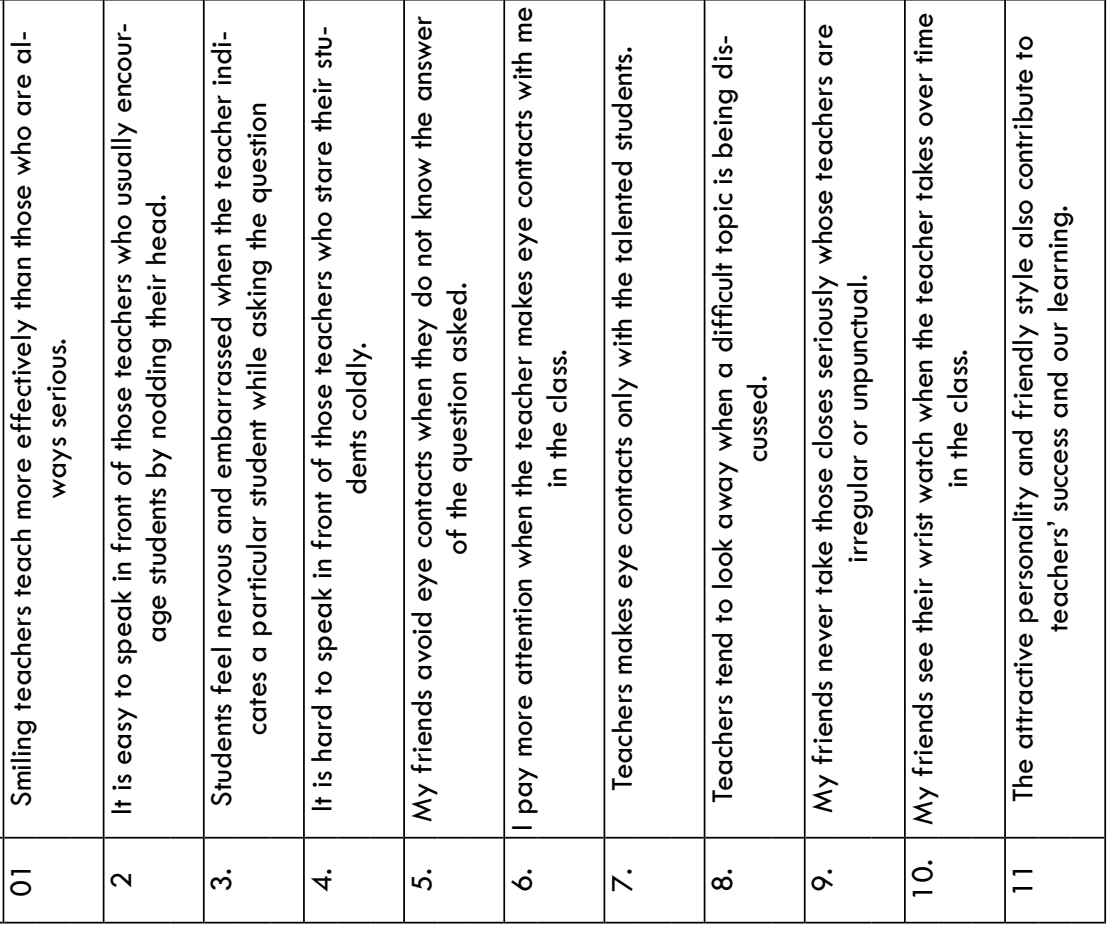



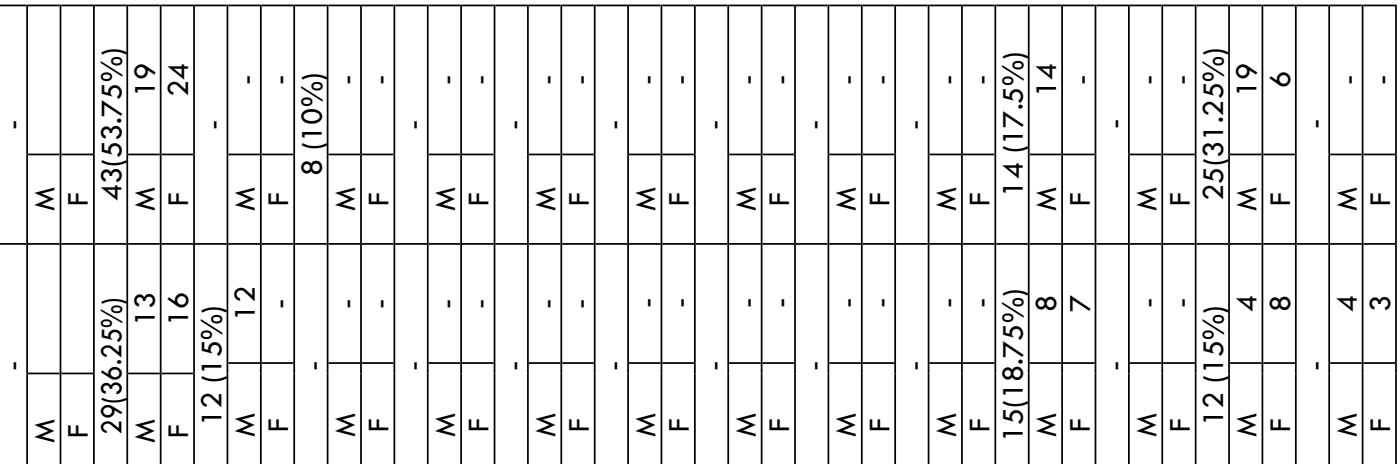

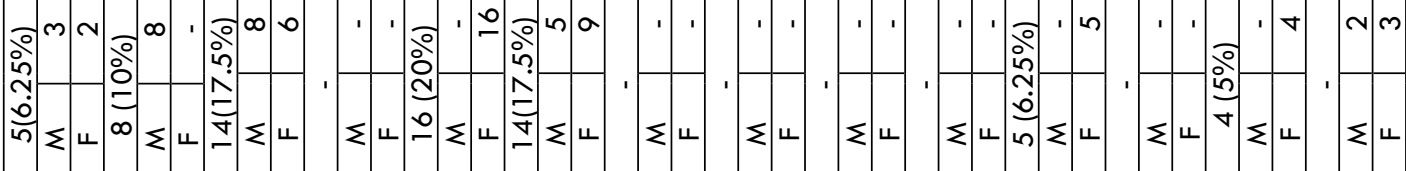

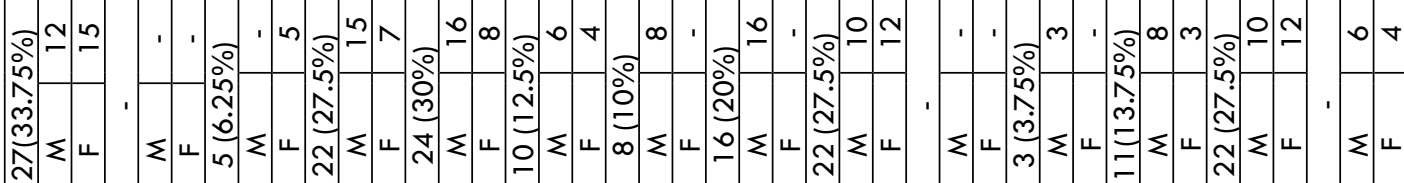

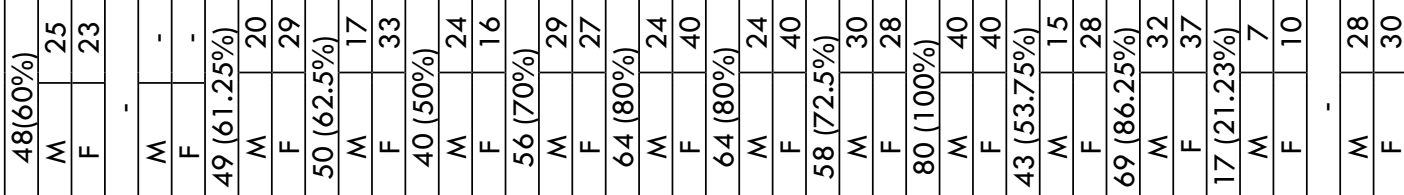

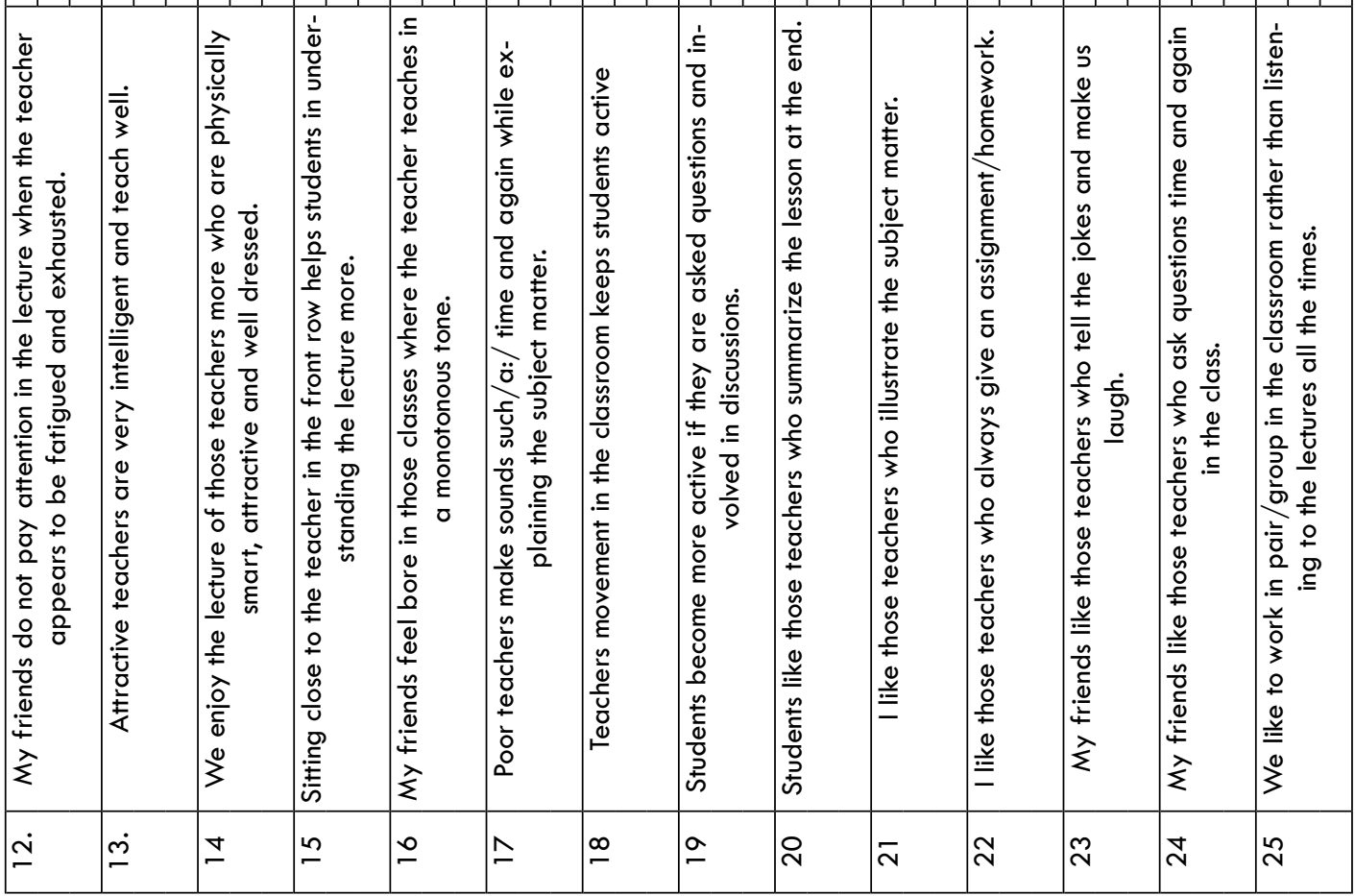




\section{Discussion}

Students (100 \%) liked teachers' smile. Analysis showed that the female students' $(60 \%$ S.A. = Strongly Agreed) motivation to teachers smile was greater than the males but they felt difficulties to speak in front of those teachers who stared at them coldly. Females (77.5\% S.A.) were highly demotivated to such teachers than the males. Students $(70 \%$ S.A.) were encouraged to speak in front of those teachers who encouraged their students by nodding their heads. In this regard, male students' (60\%) motivation to teachers' head node was greater than the females, where as majority of the students (58.75\% S.A.) felt nervous and embarrassed when the teacher indicated the particular student with their raised finger, females (77.5\%) were slightly more demotivated to such teachers than the males. Students (especially females) avoided eye contacts when they did not know the answer of the question asked but they (91.25\%) paid more attention when the teacher made eye contacts with them. Students (90\%) did not take those classes seriously, whose teachers were irregular and unpunctual. Teachers' punctuality also influenced in gender; female students were more conscious than the males in this matter. But they (75\%) looked at their wristwatch when the teacher took the over time in the class. Male students (65\% S.A.) were found less patient than the females in the classroom. Students (100\%) were highly motivated to the attractive personality and friendly style of the teachers. They also believed that attractive and frank teachers really enhance their learning. Handsomeness of the teachers did not count with their intelligence but students $(67.5 \%)$ were motivated to the attractive, smart outlook and sense of well dress of teachers. Furthermore, female students (72.5\% S.A.) were more influenced by these features of teachers than the males. Teachers' movement in the classroom kept students (90\%) active. Females (100\%) were more sensitive in this case and (82.5\%) liked to sit close (near) to their teachers. Students liked those teachers who illustrated the subject matter and summarized the lesson at the end; made them laugh in the classroom and became more active if they were asked questions and involved in discussion but they felt boredom in the class where teacher taught in a monotonous tone.

\section{Major Findings}

The analysis showed that students had both the positive and negative impact from their teachers' non-verbal communication.

i. Students were highly motivated to the teachers who smiled at them, made them laugh in the classroom, and illustrated the subject matter but felt difficulties to deal with the teacher who stared at them coldly and indicated a particular student with their raised finger.

ii. Students became more active if the teacher kept movements in the classroom and made the frequent eye contact with them.

\section{Recommendations}

Teachers should smile and node their heads to encourage their students while talking to them so that they (students) could share their difficulties, problems and so on with their teachers.

Teachers can make their students active by keeping movements in the classroom, making frequent eye contacts with them; interacting with them by asking some questions and involving them in discussion.

Good teachers are attractive, smart, and frank and make students laugh in the classroom. They illustrate the subject matter and never forget to summarize the lesson at the end and do not stare and frown at them in the classroom. So try to be a good teacher.

\section{Conclusion}

Non verbal communication is not only crucial in a plain daily communication; it is also equally important for class room situations as well. NVC, which takes various forms, illustrates or replaces certain aspects of hearers' brain that deals with the emotional part of the message. Various nonverbal behaviors of language teachers' in classroom discussed in this article so far had both the positive and negative impact on their learners' motivation. Normally, teachers constantly clarify, explain or discuss ideas; concepts and so on or simply define new terms to their students or interact with them verbally. Along with verbal behaviour if teachers 
become aware of their NVBs, it certainly helps them (teachers) to become more proficient at receiving students' messages as well as more proficient at sending accurate messages.

Janak Singh Negi is currently the Vice-Campus Chief and Lecturer of linguistics and ELT at Manilek Campus affiliated to Tribhuvan University Nepal. He has been involved in Teaching English, Teacher Training; and monitoring at various parts of Nepal. Mr. Negi is also a life member of NELTA and has served on teacher Training and monitoring for it; associated with British Council. He is particularly interested in innovative action research for teacher development and young learners in finding methods and techniques to make language teaching and learning more motivating and engaging for them $\mathrm{He}$ holds an M.Ed. degree in English Language Teaching from Tribhuvan University Nepal and Teacher training course from the British Council.

\section{References}

Abercrombie, D. (1973). Paralinguistic communication. In Allen, J.P.B. and Corder S.P. (eds.) The Edinburgh course in applied linguistics, Vol. 1. pp. (31-36).

Boyd, F.D. (2000). Non-verbal behavior of effective teachers of at-risk African American male middle school students. An Unpublished Ph.D. Dissertation, Faculty of the Virginia Polytechnic Institute and State University, Blacksburg, Virginia.

Capper, S. (2000). Non-verbal communication and the second language learner: Some pedagogic considerations. http://www.jalt-publications.org/tlt/ articles/2000/05/capper.

Christopher, E. (2002). Gender differences in non-verbal behavior. Retrieved from http://www.qnselm.edu/ internet/psych/theses/seniors2002/christopher/ webpage.html

Davis,L. (1990).Where do we stand. In Gardner, P.S. (eds.).New direction: reading, writing and critical thinking. New York: CUP.

Dunn, L.J. (1969). Non-verbal communication: information conveyed through the use of body language. Missouri: Department of Psychology. Missouri Western State University.

Gregersen, T.S. (2007). Language learning beyond words: Incorporating body language into classroom activities. Journal of Reflections on English language teaching, Vol. 6, pp. 51-64.

Harris, T.E. (2002). Applied organizational communication: Principles and pragmatics for future practice. London: Lawrence Erlbaum Associate Publishers.

Hassan, M.M.T. (2007). Non-verbal communication: The language of motivation for Pakistani students.
In Journal of Language in India. Volume 7, Aug. 2007.

Helmer, S. \& Eddy, C. (2003). Look at me when I talk to you. Toronto: Pippin Publishing Corporation.

Hickson,M. \& Stacks, D. (1993). Non-verbal communication: Studies and application. Dubuque: Wm.C.Brown.

Hymes, D.H.C.(1972). On communicativecompetence.In Pride, J.B. \& Holmes. J (eds). Sociolinguistics. England: Penguin Books Ltd.

Khan, A.A. (2001). Non-verbal communication : Fact and fiction. Retrieved from http://www.strangehorizons. com/2001/20010226/nonverbal.shtml\#top.

Khaniya, T.R. (2005). Examination for enhanced learning. Lalitpur: Millennium Publication (P) Ltd.

Knapp, M. (1972). Non-verbal communication in human interaction. New York: Holt, Rinehart and Winston.

Lewis, T.N. (2005). Gender and non-verbal communication in the foreign language classroom. tnlewis@ucdavis. edu..

Manninen, T. \& Kujanpaa, T. (2002). Non-verbal communication forms in multi-player game session. Finland: Department of Information Processing Science. University of Oulu.

Masterson, J.T. (1996). Non-verbal communication in text based virtual realities. An Unpublished M.A. Thesis, University of Montana.

Maxim, L.A. and Nowicki S.J. (2003). Developmental associations between non-verbal ability and social competence. Journal of Philosophy, Sociology and Psychology. Vol. 1, pp. 745-758.

Mehrabian, A. (1971). Silent messages. Belmont: CA; Wadsworth.

Mey, J.L. (1993). Pragmatics: An introduction. Molden: Blackwell Publishers Inc.

Miller, P. (1988). Non-verbal communication: What research says to the teacher. Washington D.C.: National Education Association.

Rosa, S.B. (2002). Understanding the role and potential impact of non-verbal communication in the primary inclusion classroom. An Unpublished Ph.D. Dissertation, Graduate School of the University of Massachusetts.

Stevick, E.W. (1982). Teaching and learning languages. Cambridge: CUP.

Woolfolk, A.\& Brooks, D. (1983). The influence of teachers' non-verbal behaviours on students' perceptions and performance. In Gordon, E. (Ed.), Review of Research in Education, Vol. 10, pp. 103-141. Washington DC. 


\section{Appendix I (Questionnaire)}

Name (optional):

Name of the college (optional):

Level: Please tick $(\checkmark)$

In the following statements you will have to tell me about your feelings regarding the non-verbal message of your language teachers as you observe them in the classroom. Please go through the statements carefully and tick $(\checkmark)$.

Under 1 if you strongly agree.

Under 2 if you agree.

Under 3 if you neither agree nor disagree.

Under 4 if you disagree and

Under 5 if you strongly disagree.

1. Smiling teachers teach more effectively than those who are always serious

$\begin{array}{lllll}1 & 2 & 3 & 4 & 5\end{array}$

2. It is easy to speak in front of those teachers who usually encourage students by nodding their head.

$\begin{array}{lllll}1 & 2 & 3 & 4 & 5\end{array}$

3. Students feel nervous and embarrassed when the teacher indicates a particular student while asking the question

$\begin{array}{lllll}1 & 2 & 3 & 4 & 5\end{array}$

4. It is hard to speak in front of those teachers who stare their students coldly.
1
2
3
4
5

5. My friends avoid eye contacts when they do not know the answer of the question asked.
1
2
34
5

6. I pay more attention when the teacher makes eye contacts with me in the class.
1
2
3
4
5

7. Teachers make eye contacts only with the talented students
1
2
3
4
5

8. Teachers tend to look away when a difficult topic is being discussed.

$\begin{array}{lllll}1 & 2 & 3 & 4 & 5\end{array}$

9. My friends never take those closes seriously whose teachers are irregular or unpunctual.
1
2
3
4
5

10. My friends see their wrist watch when the teacher takes over time in the class.

$\begin{array}{lllll}1 & 2 & 3 & 4 & 5\end{array}$

11. The attractive personality and friendly style also contribute to teachers' success and our learning

$\begin{array}{lllll}1 & 2 & 3 & 4 & 5\end{array}$

12. My friends do not pay attention in the lecture when the teacher appears to be fatigued and exhausted.

$\begin{array}{lllll}1 & 2 & 3 & 4 & 5\end{array}$

13. Attractive teachers are very intelligent and teach well. 
$\begin{array}{lllll}1 & 2 & 3 & 4 & 5\end{array}$

14. We enjoy the lecture of those teachers more who are physically smart, attractive and well dressed.

$\begin{array}{lllll}1 & 2 & 3 & 4 & 5\end{array}$

15. Sitting close to the teacher in the front row helps students in understanding the lecture more.

$\begin{array}{lllll}1 & 2 & 3 & 4 & 5\end{array}$

16. My friends feel bore in those classes where the teacher teaches in a monotonous tone.
1
2
3
4
5

17. Poor teachers make sounds such en/a: / time and again while explaining the subject matter.

$\begin{array}{lllll}1 & 2 & 3 & 4 & 5\end{array}$

18. Teachers movement in the classroom keeps students active

$\begin{array}{lllll}1 & 2 & 3 & 4 & 5\end{array}$

19. Students become more active if they are asked questions and involved in discussions.

$\begin{array}{lllll}1 & 2 & 3 & 4 & 5\end{array}$

20. Students like those teachers who summarize the lesson at the end.

$\begin{array}{lllll}1 & 2 & 3 & 4 & 5\end{array}$

21. I like those teachers who illustrate the subject matter.

$\begin{array}{lllll}1 & 2 & 3 & 4 & 5\end{array}$

22. I like those teachers who always give an assignment/homework.

$\begin{array}{lllll}1 & 2 & 3 & 4 & 5\end{array}$

23. My friends like those teachers who tell the jokes and make us laugh.

$\begin{array}{lllll}1 & 2 & 3 & 4 & 5\end{array}$

24. My friends like those teachers who ask questions time and again in the class.

$\begin{array}{lllll}1 & 2 & 3 & 4 & 5\end{array}$

25. We like to work in pair/group in the classroom rather than listening the lectures all the times.

1

$2 \quad 3 \quad 4$

5

${ }^{*}$ NAND $=$ Neither agree nor disagree 